\section{Evidence summary: what do dentists mean by 'prevention' when applied to what they do in their practices?}

\author{
Original question submitted by Wayne Richards, January 2010 \\ Reviewer: Chris Fox' \\ Information Scientist: Helen Nield
}

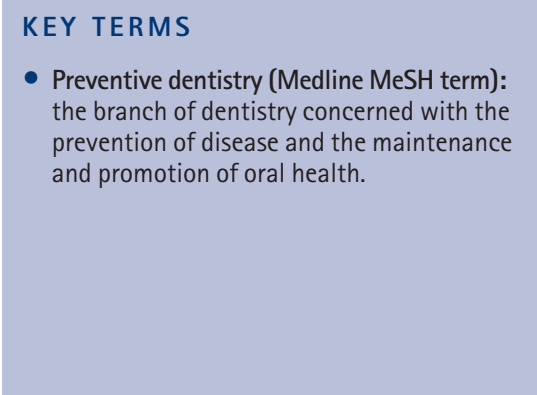

In December 2009, members of the newly redeveloped Primary Care Dentistry Research Forum (www.dentistryresearch. org) took part in an online vote to identify questions in day-to-day practice that they felt most needed to be answered with conclusive research. The question which received the most votes formed the subject of a critical appraisal of the relevant literature. Each month a new round of voting takes place to decide which further questions will be reviewed. Dental practitioners and dental care professionals are encouraged to take part in the voting and submit their own questions to be included in the vote by joining the website.

This paper details a summary of the findings of the fourth critical appraisal. In conclusion, there is a lack of evidence relating to dentists' perceptions of prevention and its application in practice. Qualitative primary research is needed to look at UK dentists' views and attitudes relating to their understanding of prevention and its application in practice.

\section{BACKGROUND}

Preventing oral disease is considered desirable and feasible ${ }^{1}$ and has been practised by dentists for over a century. ${ }^{2}$ Clarification of the meaning and practice of "preventive dentistry" ${ }^{3,4}$ is an enduring challenge to the profession. ${ }^{1}$

Recent government reform of dental services envisages dentistry as an integral part of the wider primary care network, with promotion of preventive practice being a priority. ${ }^{5}$ Emerging NHS primary care trust (PCT) commissioning arrangements ${ }^{6}$ include oral health improvement and prevention as part of dental services commissioning.

Evidence-based approaches to preventive dentistry are widely published, ${ }^{7,8}$ however accessing dentists' views about what constitutes prevention and preventive activity in their practices may pro-

${ }^{1}$ PhD Student, Peninsula Dental School Correspondence to: Beth Caines, Shirley Glasstone Hughes Trust Fund Administrator, British Dental Association, 2 Caspian Point, Cardiff Bay, CF10 4D0 Email: b.caines@bda.org; Tel: +44 (0)29 20436184 Sponsored by the Shirley Glasstone Hughes Trust

DOI: 10.1038/sj.bdj.2010.371 mote clarity both within the profession and in wider representation.

\section{AIM}

This review aimed to identify, evaluate and summarise UK primary research studies which are one of the following:

- Studies asking dentists directly what they consider prevention/preventive dentistry to involve in their practice, or what preventive activities these dentists undertake within their practice

- Surveys of dentists which include open questions about what preventive activities they do in their practices

- Surveys of dentists which include questions about oral/dental health education/promotion as a sub-set of prevention.

\section{REVIEW METHOD}

An initial search was made of Ovid MEDLINE (1950 to week 5, December 2009) using the following search terms:

- Preventive dentistry, dentists' practice patterns, general practice, dental, Great Britain. Forty-three papers identified, 39 excluded
- Preventive dentistry, definition. Four papers identified, four excluded

- Preventive dentistry, reviews 1999-2010, general articles 2005-2010, Great Britain. Fifty-six papers identified, 54 excluded.

Further searches were performed using CEBD, Cochrane Oral Health Group, ADA and National Library for Public Health, but no new papers were identified. Searches were then performed using Science Direct, ASSIA (CSA), Web of Science, EBSCO and SwetsWise, and three additional papers were identified.

\section{FINDINGS}

There appears to be no clear or consistent primary research into UK dentists' views and attitudes relating to their understanding of prevention and its application in practice. Studies with a main focus on other issues, such as dentists'/practices' attributes affecting patient well-being ${ }^{9}$ or reasons for changing public/private mix of work ${ }^{10}$ reveal other concepts relating to prevention, rather than prevention itself. Most of these studies' findings 
are constrained by the predominantly closed, quantitative methods of data collection used.

The literature found ${ }^{9-17}$ indicates a number of dimensions along which dentists' perceptions of prevention can be located (Fig. 1). Most dentists regarded aspects of prevention to be part of their professional work, ${ }^{9,12}$ a source of job satisfaction ${ }^{13}$ and of value to the practice, its image ${ }^{13}$ and a marker of quality of care. ${ }^{10}$ However, the quantity and proportion of working time spent undertaking preventive activity varied widely, ${ }^{12}$ and activity data sources may be unreliable. ${ }^{16,17}$ Historically, it appears that preventive activity was mainly related to clinical use of preventive products, for example fluoride, ${ }^{13,15}$ although visual aids for dental health education, including posters and pamphlets, were reportedly used almost 35 years ago. ${ }^{15}$ Fissure sealants and fluoride mouthrinsing advice remain popular, ${ }^{13}$ along with advice for interdental cleaning and use of fluoride toothpaste. ${ }^{14}$

More recently, dentists reported increasingly diverse perspectives upon a continuum of preventive activities, with polarisation into those of "healthfocused' dentists and of 'diseasefocused' dentists. ${ }^{11}$ The former adopted an holistic view of patients, emphasising prevention rather than treatment and feeling that the dentist's role was changing towards looking after people's general health. The biomedical, curative emphasis of 'disease-focused' dentists supported a view that any health promotion activity should be centred upon the mouth.

Other variations in perspective concerned the relevance to dentistry of specific public health interventions, for example smoking cessation or blood pressure monitoring, ${ }^{11}$ whether a general risk factor approach was appropriate, and to all patients, or if difficulties might arise in the dentist-patient relationship and therefore affect business. ${ }^{11,12}$ Also, there could be variation in provision of preventive advice with each attendance or each new course of treatment. ${ }^{14}$

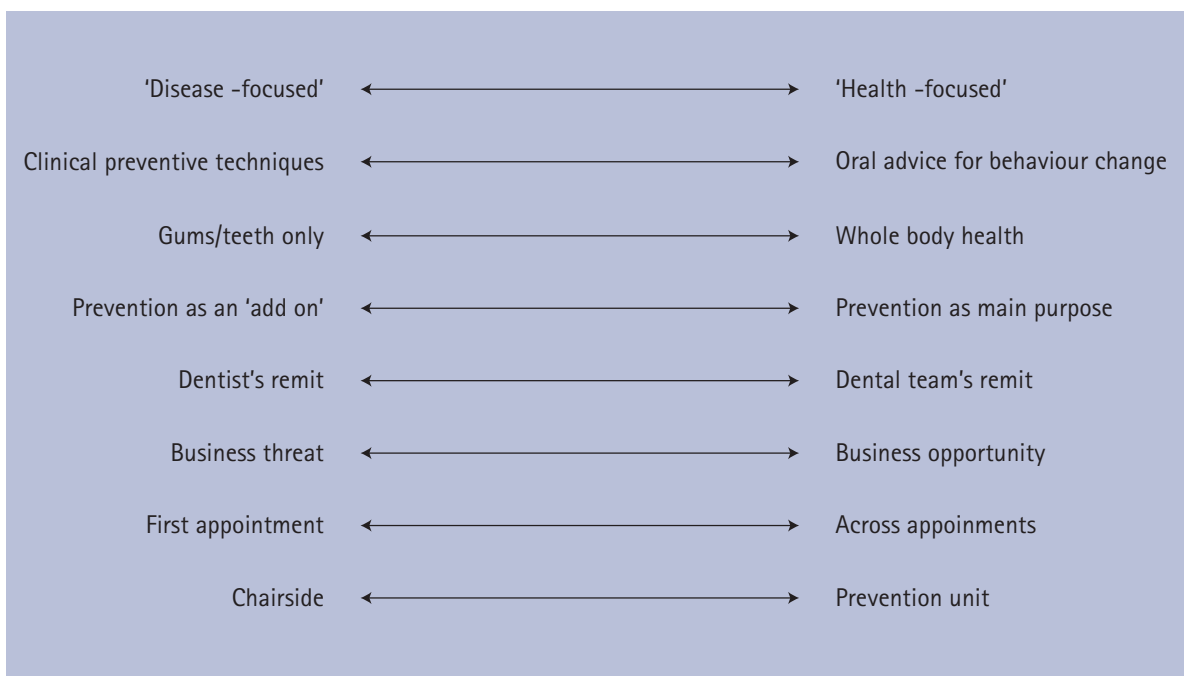

Fig. 1 Dimensions of prevention revealed by surveys and interviews with dentists

Over $50 \%$ of dentists in four of the studies felt it was desirable to give advice including oral hygiene, diet and/ or smoking prevention and cessation, even if the scientific rationale was sometimes unclear. ${ }^{13}$ However, fewer dentists viewed it as relevant to offer advice on alcohol consumption or physical activity. ${ }^{11,12,17}$

There was broad variation in the level of use of dental hygienists, ${ }^{13,14}$ although in one study practices engaged in 'patient-active prevention' (see Table 1) were almost six times more likely to employ a dental hygienist than other practices, and these practices were five times more likely to have an oral cancer screening policy. ${ }^{14}$

Most preventive advice was provided on a one-to-one basis, mainly at the chairside, ${ }^{12,14}$ with a majority also offering posters and/or leaflets. ${ }^{12,15} \mathrm{~A}$ small proportion (12\%) reported having dedicated preventive units. ${ }^{14}$

In summary, there is a lack of evidence about dentists' perceptions of prevention and its application in practice. Indicators of dentists' preventive activity yield a number of relevant dimensions and potential variations along these. Greater use of qualitative research methods within dental enquiry may lead to new insights into the views of the profession ${ }^{12,18}$ about what prevention means to them.

\footnotetext{
1. Oral health: prevention is key. [Editorial]. Lancet 2009; 373: 1
}

2. Miller J. Prevention for the individual practitioner. BrDent J 1973; 134: 181-187.

3. Lewis K J. The delivery of prevention in general dental practice. Dent Update 1981; 8: 405-415.

4. Gerrie N F. A definition of preventive dentistry. J Public Health Dent 1969; 29: 60.

5. Department of Health. NHS dentistry: options for change. London: Department of Health, 2002

6. NHS Primary Care Commissioning website, Dentistry webpage. http://www.pcc.nhs.uk/dentistry (accessed 20 January 2010).

7. Kay E J. A guide to prevention in dentistry. London: BDJ Books, 2004.

8. Department of Health/British Association for the Study of Community Dentistry. Delivering better oral health: an evidence-based toolkit for prevention. 2nd ed. London: Department of Health, 2009.

9. Kay E J, Ward N, Locker D. A general dental practice research network: impact of oral health in general dental practice patients. Br Dent J 2003; 194: 621-625.

10. Calnan M, Silvester S, Manley G, Taylor-Gooby P. Doing business in the NHS: exploring dentists' decisions to practise in the public and private sectors. Sociol Health IIIn 2000; 22: 742-764.

11. Dyer TA, Robinson P G. General health promotion in general dental practice - the involvement of the dental team. Part 2: a qualitative and quantitative investigation of the views of practice principals in South Yorkshire. Br Dent J 2006; 201: 45-51.

12. Anderson R, Treasure E T, Sprod A S. Oral health promotion practice: a survey of dental professionals in Wales. Int J Health Promotion Educ 2002; 40: $9-14$

13. Holloway P J, Clarkson J E. Cost: benefit of prevention in practice. Int Dent J 1994; 44: 317-322.

14. Freeman R, Kerr G, Salmon K, Speedy P. Patientactive prevention in primary dental care: a characterisation of general practices in Northern Ireland. Prim Dent Care 2005; 12: 42-46.

15. Rock W P, Bradnock G. Preventive dentistry in general practice. A study of current use. Br Dent J 1976; 140: 61-64.

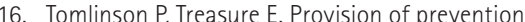
to adults in NHS dental practices and attitudes to prevention. Br Dent J 2006; 200: 393-397.

17. Warnakulasuriya KA A S, Johnson N W. Dentists and oral cancer prevention in the UK: opinions, attitudes and practices to screening for mucosal lesions and to counselling patients on tobacco and alcohol use: baseline data from 1991. Oral Dis 1999; 5: 10-14

18. Newton T. Qualitative research and evidencebased dentistry: linking evidence to practice. Evid Based Dent 2000; 2: 104-106. 


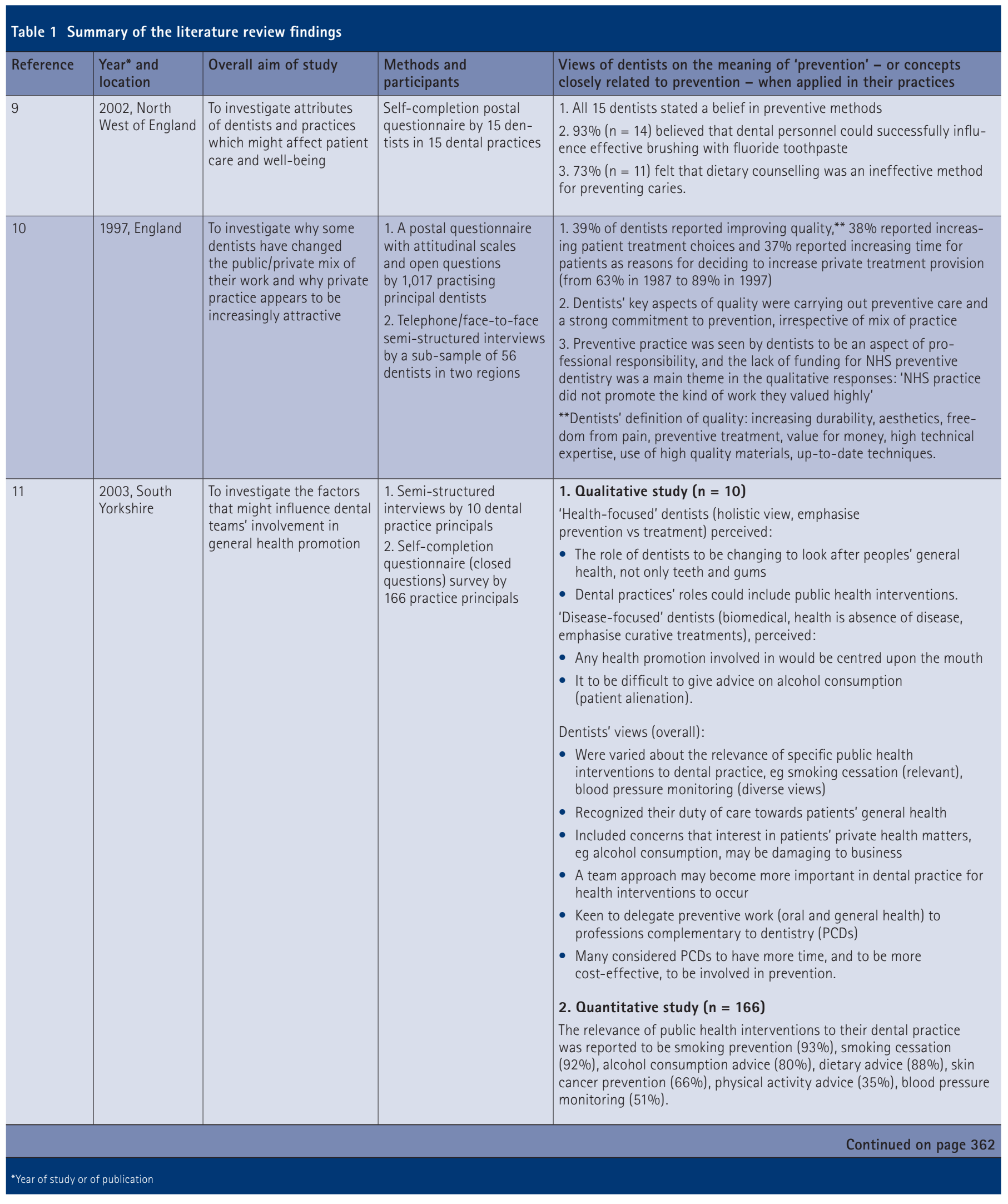


Table 1 Summary of the literature review findings

\begin{tabular}{l|l|} 
Reference & $\begin{array}{l}\text { Year* and } \\
\text { location }\end{array}$ \\
\hline \multicolumn{2}{|c|}{ Continued from page 361} \\
\hline 12 & 1996, Wales
\end{tabular}

\section{2}

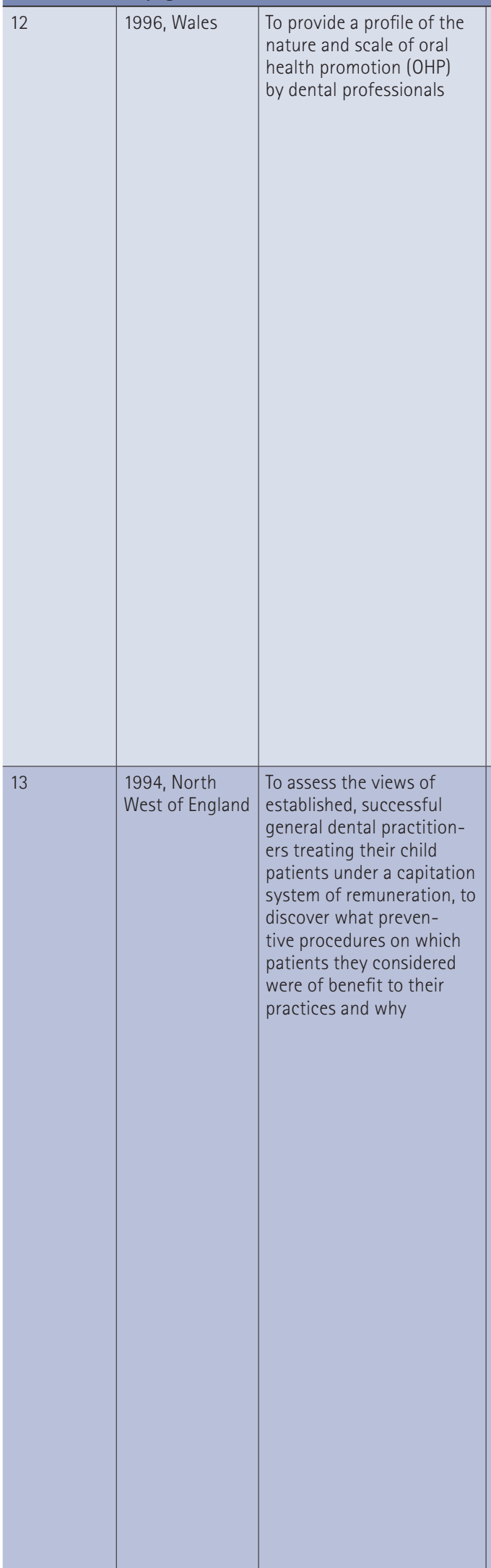

Methods and participants
Views of dentists on the meaning of 'prevention' - or concepts closely related to prevention - when applied in their practices
Self-completion questionnaire (mixed open and closed questions) survey by 568 dental professionals (dentists, dental hygienists, dental therapists)

1. Telephone interview by 50 dentists using closed questions

2. Unstructured discussion groups by 21 dentists

3. 'Standard gamble' technique questionnaire by 20 dentists
1. $89 \%$ of dentists, and $88 \%$ of all dental professionals, stated OHP formed part of their work

2. $50 \%$ of the general dental practitioners who said OHP formed part of their work spent over 2 hours per week in this activity

3. Of those who stated OHP formed part of their work $(n=492), 450$

(91\%) identified key messages they conveyed as OHP:

- $77 \%$ on oral hygiene (including efficient and regular toothbrushing (34\%), use of fluoride toothpaste/other fluoride (23\%))

- $72 \%$ on diet (sugar and sweets (28\%), usually in relation to mealtimes, snacking avoidance)

- A significant proportion promoted general rather than risk factorspecific messages, eg oral health disease is preventable, natural teeth last a lifetime, personal responsibility for oral health.

4. 430 of the respondents who stated OHP formed part of their work spent between $4 / 5$ and all of their time on the reduction or prevention of dental caries and gum disease

5. About $40 \%$ stated they spent no time on oral cancer or dental injury prevention

6. $73 \%$ of respondents who identified a target group targeted children for dental caries prevention and 78\% for dental injuries prevention; 61\% targeted the elderly for gum disease and $86 \%$ for oral cancer prevention

7. $98 \%$ of those undertaking OHP undertook one-to-one advice at the chairside. Clinical preventive techniques were second most popular,eg fissure sealants (87\%), topical fluoride applications (69\%). Other OHP techniques included offering preventive care more often/made more available $(61 \%)$, distributing educational leaflets (60\%) or displaying educational posters (58\%)

8. $23 \%$ of those undertaking OHP reported having a specific area for health education/promotion activities.

1. All 50 dentists thought that prevention in some form upon selected patients was of value to the practice

2. Some (number undisclosed) stated prevention was good for practice image; if carried out selectively it could be cost-effective relative to operative dentistry

3. All dentists agreed prevention improved their job satisfaction 4. Some (number undisclosed) dentists viewed prevention as part of modern professional philosophy and dentists were neglectful if they did not practice this on their patients

$5.88 \%$ of respondents (based upon $n=50$ of telephone interviews) selectively prescribed fluoride supplements. $48 \%$ restricted fluoride tablets to children under 10 years old with active caries, as part of participation in a comprehensive preventive regimen

$6.96 \%$ of respondents used pit and fissure sealants, although they were unsure of their cost-effectiveness and only $26 \%$ used them routinely

7. $58 \%$ of respondents viewed dietary counselling as practice-beneficial, perceiving that unless sugar intake was under control, other preventive activity would be to no avail

8. $92 \%$ gave oral hygiene demonstrations, although the rationale was unclear

9. $32 \%$ felt that applying topical fluoride preparations to patients' teeth was of value to their practice; $66 \%$ recommended daily use of fluoride mouthrinses as part of a wider caries preventive programme for adolescents

10. $52 \%$ employed dental hygienists, to whom routine procedures, eg oral hygiene demonstrations, dietary counselling, topical fluoride treatments and sealant application, were often delegated. Dentists who employed a dental hygienist had a statistically significantly higher 'mean preventive awareness score' $(p=0.02)$ - a locally developed comparative marker of practice policies on preventive procedures

11. The three most popular preventive techniques over the whole age range of patients were dietary counselling (greatest), then fissure sealants and fluoride mouthrinsing, although the ranking varied within age groups. 
Table 1 Summary of the literature review findings

\begin{tabular}{|c|c|c|c|c|}
\hline Reference & $\begin{array}{l}\text { Year* and } \\
\text { location }\end{array}$ & Overall aim of study & $\begin{array}{l}\text { Methods and } \\
\text { participants }\end{array}$ & $\begin{array}{l}\text { Views of dentists on the meaning of 'prevention' - or concepts } \\
\text { closely related to prevention - when applied in their practices }\end{array}$ \\
\hline \multicolumn{5}{|c|}{ Continued from page 362} \\
\hline 14 & $\begin{array}{l}\text { 2005, Northern } \\
\text { Ireland }\end{array}$ & $\begin{array}{l}\text { To investigate the preven- } \\
\text { tive orientation of general } \\
\text { dental practices in the } \\
\text { Eastern Health and Social } \\
\text { Services Board (EHSSB) } \\
\text { region by examining their } \\
\text { 'patient-active preven- } \\
\text { tion'*** activities, practice } \\
\text { policies for prevention and } \\
\text { employment strategies } \\
\text { ***'Patient-active preven- } \\
\text { tion': 'a dental practice } \\
\text { providing advice, counsel- } \\
\text { ling, information leaflets, } \\
\text { oral health products; } \\
\text { anything that would enable } \\
\text { patients to take an active } \\
\text { role in the management of } \\
\text { their oral health status' }\end{array}$ & $\begin{array}{l}\text { Interviewer-administered } \\
\text { closed questionnaire by } \\
128 \text { general dental practice } \\
\text { principals }\end{array}$ & $\begin{array}{l}\text { 1. Over } 90 \% \text { of dentists reported providing dietary advice for dental } \\
\text { caries, oral hygiene instruction, advice on fluoride toothpaste use } \\
\text { and interdental cleaning instruction. Also information on dental } \\
\text { erosion and sugar-free medicines when felt appropriate for patients' } \\
\text { oral health needs } \\
\text { 2. } 78 \% \text { of dentists provided information on mouthguards, and } 75 \% \\
\text { provided information on smoking cessation when they felt these } \\
\text { interventions were appropriate for patients' needs } \\
\text { 3. Fewer dentists provided oral health advice with each new course } \\
\text { of dental treatment (diet for dental caries 3\%, oral hygiene instruction } \\
\text { 7\%, fluoride toothpaste use } 7 \% \text { and interdental cleaning } 7 \% \text { ) } \\
\text { 4. Provision of oral health education was reported as part of practice } \\
\text { policy for } 95 \% \text { of respondents, with } 88 \% \text { providing one-to-one oral } \\
\text { health advice. In addition, } 73 \% \text { provided oral health information in } \\
\text { waiting areas, } 64 \% \text { oral hygiene products and } 63 \% \text { oral health } \\
\text { education leaflets } \\
\text { 5. } 12 \% \text { of practices had a dedicated preventive unit } \\
\text { 6. } 21 \% \text { of practices employed a dental hygienist. Practices that employed } \\
\text { hygienists tended to have a higher 'prevention-activity score' (a scoring } \\
\text { of the frequency of provision of 'patient-active prevention' items) } \\
\text { 7. 'Patient-active prevention' practices were } 5.8 \text { times more likely to } \\
\text { employ a hygienist, and } 5.3 \text { times more likely to have an oral cancer } \\
\text { screening policy than non-'patient-active prevention' practices. }\end{array}$ \\
\hline 15 & $\begin{array}{l}\text { 1976, England, } \\
\text { Wales and } \\
\text { Scotland }\end{array}$ & $\begin{array}{l}\text { 1. To assess the numbers of } \\
\text { dentists using preventive } \\
\text { methods, and } \\
\text { 2. To assess the attitude of } \\
\text { the profession towards a } \\
\text { suggested inclusion of fees } \\
\text { for preventive therapy on } \\
\text { the NHS scale }\end{array}$ & $\begin{array}{l}\text { A closed postal question- } \\
\text { naire }{ }^{\ddagger} \text { by } 885 \text { dentists } \\
\text { f Primarily aimed at pre- }_{\text {vention of dental caries }}\end{array}$ & $\begin{array}{l}\text { 1. } 80 \% \text { (706) dentists reported using preventive products } \\
\text { 2. Use of preventive techniques was positively statistically associated } \\
\text { with university training in their use ( } p<0.0005) \text {, with preventive meas- } \\
\text { ures employed by } 94 \% \text { of those qualified since } 1970 \\
\text { 3. Application of fluoride to the teeth (gel/solution/mouthrinse/fluori- } \\
\text { dated polishing paste/fissure sealant) was the basis of most } \\
\text { preventive treatments, with gel use ( } 85 \%) \text { predominant and } \\
\text { mouthrinse lowest ( } 9 \%) \\
\text { 4. } 82 \% \text { of dentists who stated they used preventive products used } \\
\text { visual aids for patient dental health education, while at least } 60 \% \text { used } \\
\text { posters, pamphlets and plaque-disclosing agents. } 7 \% \text { reported having a } \\
\text { 'cassette viewer' in the surgery/waiting room. }\end{array}$ \\
\hline 16 & 2003, Wales & $\begin{array}{l}\text { 1. To establish the cur- } \\
\text { rent level of provision of } \\
\text { reimbursed preventive care } \\
\text { to adult NHS patients in } \\
\text { Wales, and } \\
\text { 2. To determine the reasons } \\
\text { why dentists do or do not } \\
\text { claim payment for provid- } \\
\text { ing such care }\end{array}$ & $\begin{array}{l}\text { A closed question postal } \\
\text { questionnaire by } 267 \\
\text { dentists in general dental } \\
\text { practice } \\
\text { Also the Dental Practice } \\
\text { Board (DPB) data routinely } \\
\text { collected in Wales for } \\
\text { three Statement of Dental } \\
\text { Remuneration (SDR) codes } \\
\text { relating to adult preventive } \\
\text { care for the year ended } \\
\text { October } 2002\end{array}$ & $\begin{array}{l}\text { 1. Respondents' awareness of the SDR codes was } 86 \% \text { for fissure } \\
\text { sealants (FS), } 64 \% \text { for intensive oral health instruction (OHI) } \\
\text { (including dietary advice and oral hygiene techniques), and } 54 \% \text { for } \\
\text { topical fluoride (TF) } \\
\text { 2. Of these code-aware dentists, } 17 \% \text { (FS), } 56 \%(\mathrm{OHI}) \text { and } 1.4 \% \text { (TF) } \\
\text { had claimed for them in the past three months } \\
3.94 \% \text { of dentists considered } \mathrm{OHI} \text { was the most appropriate form of } \\
\text { oral health promotion for dentists to provide, } 88 \% \text { to provide advice on } \\
\text { fluoride use, and } 85 \% \text { to give dietary advice specifically in relation to } \\
\text { low sugar and erosive foods } \\
\text { 4. } 59 \% \text { of dentists were open to providing smoking cessation advice and } \\
51 \% \text { to providing general health dietary advice. } 21 \% \text { felt it was appropri- } \\
\text { ate to provide advice relating to drug and alcohol addiction. }\end{array}$ \\
\hline 17 & $\begin{array}{l}\text { 1991, United } \\
\text { Kingdom }\end{array}$ & $\begin{array}{l}\text { To assess the attitudes } \\
\text { to, and practice of, oral } \\
\text { mucosal examination and } \\
\text { the provision of profes- } \\
\text { sional advice aimed at } \\
\text { primary prevention of oral } \\
\text { cancer }\end{array}$ & $\begin{array}{l}\text { A mailed questionnaire by } \\
2,519 \text { regular UK recipients } \\
\text { of the British Dental Jour- } \\
\text { nal (response rate } 16 \% \text { ) }\end{array}$ & $\begin{array}{l}\text { 1. Half of respondent dentists did not routinely enquire about cigarette } \\
\text { smoking and alcohol consumption habits. Of those who did, } 30 \% \text { of } \\
\text { dentists enquired of smoking habit and } 19 \% \text { of both smoking and } \\
\text { alcohol habits. } 19 \% \text { recorded this data in patients' notes } \\
\text { 2. } 30 \% \text { of dentists who enquired into smoking habits provided brief } \\
\text { advice routinely to their patients; in addition, } 31 \% \text { of dentists provided } \\
\text { advice to patients considered to be at high risk of oral cancer or other } \\
\text { major disease } \\
\text { 3. } 20 \% \text { of dentists tried to give alcohol consumption moderation advice } \\
\text { to patients where its consumption appeared excessive } \\
\text { 4. } 71 \% \text { of dentists felt it was desirable to provide advice against tobacco } \\
\text { use, however perceived constraints included: unimportant, ineffective so } \\
\text { also frustrating, not cost effective, lacked training. }\end{array}$ \\
\hline
\end{tabular}

